\title{
Acquisition of novel traces in short-term implicit memory: Priming for nonwords and new associations
}

\author{
ELINOR MCKONE and KRISTINA TRYNES \\ Australian National University, Canberra, Australia
}

\begin{abstract}
McKone (1995) reported a short-lived repetition priming effect (up to 8 sec and three intervening items), superimposed on long-term priming. In lexical decision and naming, decay of this short-term implicit memory was faster for pseudowords than for words, suggesting an explanation in terms of transient activation of preexisting lexical representations. Here, we present two cases where, in contrast, preexperimental familiarity did not affect short-term priming, indicating acquisition of novel traces. Experiment 1 determined repetition priming in same-different judgments to lowercaseuppercase pairs for words, and for nonwords with three levels of wordlikeness. Across lags of 0,1 , and 6 intervening items (2-14 sec), short-term priming was the same for all stimuli, even random letter strings. Experiments 2 and 3 assessed priming in a double lexical decision task for old associations (orange-apple) and new associations (cigar-errand). Short-term priming for the association was equal in both cases.
\end{abstract}

Implicit memory differs from explicit memory in the nature of the retrieval process (Graf \& Schacter, 1985). Explicit retrieval occurs in recall or recognition tasks, in which the subject deliberately and consciously recollects information from a prior episode. Implicit retrieval occurs when there is a change in task performance attributable to some prior event that is independent of any conscious recollection of that event; for example, repetition priming is revealed when prior exposure speeds word-nonword decision times in a lexical decision task (Kirsner \& Smith, 1974; Scarborough, Cortese, \& Scarborough, 1977).

Explicit memory is commonly separated into two components: a short-term (or working memory) component and a long-term component (for review, see Baddeley, 1990). Recently, McKone (1995) and Maljkovic and Nakayama (1994) have made an analogous distinction between short- and long-term forms of implicit memory, with the duration of implicit short-term memory similar to that of explicit short-term memory. It is this short-term implicit memory that is of interest in the present work (for reviews of long-term implicit memory, see RichardsonKlavehn \& Bjork, 1988; Roediger \& McDermott, 1993; Schacter, 1987; Tenpenny, 1995). Note that our use of the label short-term implicit memory is a descriptive one only,

This work was partially supported by Grant FRFN9508 from the Australian National University and Grant F96058 from the Australian Research Council. We thank Lainie Hart and Matthew O'Connor for testing subjects in Experiment 3, and Michael Cook, Gay Snodgrass, Steve Smith, M. S. Weldon, L. Light, Molly Potter, and an anonymous reviewer for thoughful comments on earlier versions of this manuscript. Correspondence should be addressed to E. McKone, Division of Psychology, Australian National University, Canberra, ACT 0200, Australia (e-mail: elinor.mckone@anu.edu.au). reflecting the duration of the memory and the presumed nature of retrieval: No assumption is necessarily made regarding separate systems or stores.

Short-term implicit memory has been demonstrated using a lag paradigm (Kirsner \& Smith, 1974), in which a continuous list of trials is presented, subjects are required to respond to every trial, and particular stimuli are repeated after various numbers of intervening trials. Maljkovic and Nakayama (1994) used this technique to identify a shortterm priming effect in visual search for odd-one-out targets (e.g., a red diamond among green diamonds), based on repetition of the identifying property of the target (red) across successive trials. The repetition advantage decayed smoothly over approximately four intervening trials $(12 \mathrm{sec})$. The effect was not influenced by the trial-totrial predictability of the identifying property or by subjects' conscious attempts to make use of this predictability, providing evidence of the implicit nature of the effect. Maljkovic and Nakayama (1998) further found that subjects' conscious recollection of the target on previous trials was at chance after one intervening item, despite substantial priming at this lag.

McKone (1995) investigated short-term priming for words and nonwords. Items were presented for lexical decision at lags of $0,1,2,3,4,5,9$, and 23 intervening items at a rate of $2 \mathrm{sec}$ per trial. The basic finding was that priming for real words decayed rapidly but smoothly over three or four intervening trials $(8-10 \mathrm{sec})$, while priming for highly wordlike nonwords ( $p$ seudowords ${ }^{1}$ such as mave) decayed to the long-term value with a single intervening item. This pattern was replicated with both lexical decision and naming (speeded reading aloud) tasks, and for low- and highfrequency words. These results demonstrated a rapidly decaying short-term priming effect for lexical stimuli. 
McKone (1995) argued that short-term priming does not simply reflect the same mechanisms as those underlying short-term explicit memory or long-term implicit memory. With respect to the distinction between shortterm priming and explicit memory, it was shown that the decay patterns of explicit recognition (old-new decision) did not match those in the tasks assumed to elicit implicit retrieval: Specifically, there was no lag $\times$ lexicality interaction. Recognition decisions were also substantially slower than lexical decision and naming responses, suggesting that any explicit recall of earlier items was unlikely to be responsible for the repetition advantage on the lexical decision and naming tasks. With respect to the distinction between short-term priming and long-term priming, it was found that short-term priming for very high frequency words existed in the absence of any long-term priming (i.e., priming reached zero beyond approximately lag 4). Further, the manipulation of word frequency dissociated short-term and long-term priming: Short-term priming for high-frequency words was of the same magnitude and had the same decay rate as for low-frequency words.

McKone (1995) argued that, at least for lexical stimuli known to exhibit priming even at long delays, total priming at any lag is made up of a sum of two components: long-term priming present at all lags and short-term priming available prior to perhaps lag 4 . The evidence for this was that increasing word frequency simply reduced total priming at lags $1-4$ by a constant equal to the difference in long-term priming between low- and high-frequency words (i.e., short- and long-term priming were "independent and additive"). A methodological implication of this view is that priming at lags $0-3$ does not provide a direct measure of short-term priming; rather, the amount of short-term priming must be determined as the amount of priming at these lags over and above the stable long-term value. A theoretical implication is that the relationship between short-term priming and long-term priming is not one of separate "stores," where items are in one store prior to lags 3-4, and are transferred to another after this point. Instead, it appears that an item can produce both shortand long-term priming effects simultaneously. ${ }^{2}$

The lag $\times$ lexicality interaction reported by McKone (1995) is of particular relevance to the present research, and more recent work in this laboratory has extended our understanding of the finding of weaker short-term priming for pseudowords. McKone and Dennis (1998) replicated the lag $\times$ lexicality interaction in lexical decision with visual presentation, but demonstrated smooth decay over several intervening items for both words and pseudowords with auditory presentation. In combination with the naming data of McKone (1995), these results dissociate the finding of an effect of lexical status from the use of the lexical decision task, and thus show that the lag $\times$ lexicality interaction cannot be attributed simply to the opposite decisions made to words and nonwords. McKone (1998) demonstrated that the lag $\times$ lexicality interaction arises primarily because nonword traces are particularly sensitive to interference from intervening items, rather than because they undergo more rapid spontaneous decay.

\section{Role of Preexisting Representations in Short-Term Priming}

In long-term implicit memory, the role of stimulus novelty in producing the repetition benefit has been strongly debated (e.g., Bowers, 1994; Carr \& Brown, 1990; Tenpenny, 1995). At a theoretical level, Bowers (1994) characterized this debate as turning on whether priming relies on modification of preexisting representations or acquisition of novel memory traces. ${ }^{3}$ Under a modification view (e.g., Graf \& Mandler, 1984; Morton, 1969), repetition priming is the result of activating, strengthening, or perhaps lowering the threshold of preexisting memory representations. For example, when a familiar word is presented for the first time within the experiment and activates its permanent representation in the subject's lexicon, this activation might endure for some time so that access to the representation is easier on a second presentation. When a novel item such as a random letter string is presented, in contrast, no word unit is available to be modified, and no priming results.

Alternatively, it has been argued that long-term priming is the result of a new episode-specific memory trace that is created by the item's first presentation. Such acquisition theories propose that priming then results to the extent that reuse of the study processing procedures at test cue retrieval of the prior memory trace (e.g., Jacoby, 1983; Morris, Bransford, \& Franks, 1977; Roediger, 1990). Under this view, priming should extend to unfamiliar stimuli. In the extreme case, it would be possible for random letter strings to show as much priming as real words, and such a finding would clearly indicate acquisition of novel traces.

Thus, in long-term implicit memory, the role played by preexisting representations has been of considerable theoretical interest. The empirical data regarding the effects of stimulus novelty on long-term priming are rather contradictory (see Tenpenny, 1995, for review), but a pure modification explanation of such priming can be discarded simply on the basis of its duration (Schacter, 1987). Priming that endures for days or weeks is difficult to explain in terms of transient activation of abstract word units because the leftover activation necessary to produce longlasting priming for hundreds of items would severely interfere with the processing of newly presented words in normal reading (Grossberg, 1980; McClelland \& Rumelhart, 1988, p. 16).

The duration of short-term priming, in contrast, is perfectly consistent with leftover activation (or some other modification mechanism), since a word recognition system might reasonably be able to hold three or four items active at once without suffering catastrophic interference. Further, such an ability would be of real value for tasks such as sentence processing. Short-term priming, there- 
fore, would appear a priori to be a prime candidate for an effect resulting from the transient modification of preexisting representations.

The effects of preexperimental familiarity on short-term priming reported to date are consistent with a modification account. McKone $(1995,1998)$ and McKone and Dennis (1998) have all shown a sharp difference in the decay patterns of short-term priming between words and pseudowords; using lexical decision and naming tasks. The weaker priming for pseudowords indicates that explanations of short-term priming in these tasks must include some role for word-level representations that exist prior to the experiment. Indeed, theoretical discussion of shortterm priming in two studies by McKone $(1995,1998)$ was based on the premise that short-term priming arises through transient changes in the state of units or connections within the word recognition system.

In the present article, in contrast, we present two cases in which short-term priming was not affected in any way by stimulus novelty. These cases employed different combinations of stimuli and tasks from those previously reported. In showing that preexisting representations do not always influence short-term priming, we demonstrate that short-term priming can, under certain circumstances at least, rely on the acquisition of novel traces that do not reference preexisting representations. This demonstration is of interest because it argues against a straightforward activation account even of short-term priming.

\section{The Present Study}

The present experiments examined the role of preexisting representations in short-term priming by measuring the repetition benefit across lags 0,1 , and 6 as a function of the novelty of two classes of stimuli. The experiments are presented here together because, in both cases, stimulus novelty did not affect short-term priming in any way: That is, the amount of priming at lags 0 and 1 over and above priming at lag 6 (the presumed long-term value) did not differ for novel and preexperimentally familiar stimuli.

In Experiment 1, we varied the wordlikeness of single four-letter strings across four different levels, ranging from words through to random letter strings (e.g., frog, mave, madl, $f t g l)$. The task differed from the lexical decision and naming tasks used in McKone (1995); instead, required an across-case same-different judgment about pairs of letter strings (e.g., "yes" to mave-MAVE vs. "no" to mave-SIME). In Experiments 2 and 3, individual target items were always real words, but they were presented as paired associates with the pairing between words being either familiar or novel (e.g., orange-apple, cigar-errand). The task in this case was double lexical decision (e.g., "yes" to cigar-errand vs. "no" to house-nable). Although common in studies of long-term priming, shortterm priming for such old and new associations has not previously been examined.

Before the experiments are presented, some comment on the definition of novel stimulus is warranted. In previous studies of long-term implicit memory, both non- words (Bowers, 1994; Cermak, Talbot, Chandler, \& Wolbart, 1985; Diamond \& Rozin, 1984; Dorfman, 1994) and new associations (Carroll \& Kirsner, 1982; Graf \& Schacter, 1985; McKoon \& Ratcliff, 1979) have been used as "novel" stimuli to assess the role of preexperimental familiarity in priming. Although we consider it reasonable to assume that new associations constitute a unit that enters memory for the first time during the study episode, a qualification regarding the novelty status of nonwords is necessary (Bowers, 1994; Dorfman, 1994). Implicit memory researchers have often made the oversimplified assumption that words have preexisting representations and nonwords do not (e.g., Roediger \& McDermott, 1993; Schacter, 1987). The unspoken premise underlying this view is that discrete whole-word representations exist for each word in our vocabulary and that these are serially searched to match the stimulus (Forster, 1976). Because no lexical entry is available for nonwords, it is then assumed that nonwords cannot activate preexisting representations.

The development of parallel (e.g., McClelland \& Rumelhart, 1981) and distributed (e.g., Seidenberg \& McClelland, 1989) access models of word recognition, however, suggests that some types of nonwords have access to word-level representations. In these models, any letter string partially activates the representations corresponding to similarly spelled real words. For example, in McClelland and Rumelhart (1981), the pseudoword mave partially activates representations of words sharing letters in the same position, such as have, cave, and mate. By most current models of word recognition, then, priming for pseudowords is perfectly consistent with modification of preexisting representations. The modification view would, however, be falsified if priming for highly unwordlike letter strings were as strong as priming for real words: The former share no sublexical components with real words and should, by any model, produce very little word-level activation.

\section{EXPERIMENT 1}

Experiment 1 investigated the role of preexisting representations in short-term priming for four-letter items varying in their orthographic similarity to English. Real words and three types of nonwords were presented, which became progressively less wordlike in orthographic structure (none, one, or many violations of legal orthography ${ }^{4}$ ) and thus in likelihood of activating either whole-word or sublexical representations. Subjects were presented with two items at once, in different case, and were required to respond "same" if the two items had the same identity (e.g., $x y f l$-XYFL), and "different" otherwise (e.g., maveSIME). Priming was measured as the reduction in reaction time to the second presentation of same pairs compared with reaction time to the first presentation. Different trials were discarded.

The same-different task has not generally been used to examine repetition priming. We introduced it because, at the time of conducting the experiment, we had some 
doubts about the use of the lexical decision task for examining priming for nonwords given the possibility that a repeated no decision might be more difficult because of the increased familiarity of the nonword on second presentation (see Bowers, 1994; Dorfman, 1994; Feustel, Shiffrin, \& Salasso, 1983). As noted earlier, we now have evidence that the lag $\times$ lexicality interaction is not dependent on the use of the lexical decision task, and so cannot in fact be attributed to such a "familiarity bias." Our original motivation for the same-different task, however, was that it required an identical response (same) to all target items.

One issue arising with the choice of the same-different task was that a priori, it was not necessarily the case that the task would produce access to preexisting representations at "study," a fundamental requirement if the role of such representations in short-term priming is to be addressed. Unlike lexical decision and naming, the samedifferent task could be performed without any necessary reference to an internal lexicon, simply by comparing letters on a one-by-one basis. It is well known, however, that lexical-level information can sometimes be recruited even when it is not technically required by the task. For example, in the word superiority effect (Reicher, 1969; Wheeler, 1970), degraded letters are identified more accurately if they form part of a word or pseudoword than if they are presented in a random letter string. We felt that a similar use of lexical-level knowledge was likely to occur in our same-different task, given that subjects were required to perform the task as rapidly as possible. This assumption can be examined empirically. If the samedifferent task does produce differential access to preexisting representations, then first presentation (i.e., unprimed) reaction times should increase progressively as a function of decreasing wordlikeness. Such a finding would also provide empirical support for our presumed ordering of the wordlikeness conditions.

Assuming that the pattern of first presentation reaction times observed validates our choice of task and manipulation of wordlikeness, repetition priming can be examined. If short-term priming relies on modification of preexisting representations, a decrease in the amount of short-term priming should be observed with a decrease in wordlikeness. For example, the level of lag 0 priming (over and above the lag 6 value) might decrease with decreasing wordlikeness or, alternatively, faster decay at lag 1 might occur. In contrast, clear evidence for the acquisition of new traces would be obtained if equivalent patterns of short-term priming were found for all items, regardless of their degree of novelty.

\section{Method}

\section{Subjects}

Sixteen 1st-year undergraduate psychology students attending the Australian National University participated in return for course credit. All subjects reported English as their native language, and had normal or corrected-to-normal vision.

\section{Design}

A $4 \times 3$ repeated measures factorial design was used, with wordlikeness (words, pseudowords, partly legal nonwords, and illegal nonwords) crossed with lag $(0,1$, and 6). Priming was measured as the reduction in reaction time, in a same-different task, to the second presentation of a target pair compared with the first.

\section{Materials}

Manipulation of lag. Lag conditions were presented in a different random order to each subject and were not overlapped (i.e., targets in one condition did not serve as intervening items for other conditions). An initial template of condition codes was specified containing minisequences of trials necessary for each of 25 occurrences of each condition. For example, a lag 6 pseudoword minisequence required eight trials: These contained a code for a target pseudoword, then six trials of codes for fillers of various types, then a code for the repeat of the target. A full sequence template for each subject, defining the order of all trial types to be presented, was then created by randomizing the order of minisequences within the initial template. This procedure ensured that any practice or fatigue effects over the length of the list affected all lag conditions equally, and also removed the possibility of consistent order effects of one trial on the next.

For each subject, particular items were then randomly selected to appear in particular conditions (see below), giving a complete list of filled trials for that subject. The complete list of 1,428 trials was split into five blocks for presentation, with first and second presentations of repeated items never split across blocks. There was a maximum of 300 trials per block.

Manipulation of wordlikeness. All items were four letters long. Items in the word condition were of low to medium frequency (4-26 occurrences per million in Kučera and Francis, 1967). Of the 480 possible words from this frequency range, 80 were excluded for various reasons (e.g., offensive words, proper names), leaving a pool of 400 words. Items in the pseudoword condition made up 400 strings that were pronounceable and obeyed the orthographic rules of English (e.g., mave), but that were not homophones of real English words. The partly legal nonword condition was composed of 400 items that were somewhat pronounceable and were produced by changing one letter in a real four-letter English word to create one violation of English orthography (e.g., madl from the word made). Finally, the illegal nonword condition was composed of 400 items that were completely unpronounceable and had multiple violations of English orthography (e.g., $x y f l$ ). These were produced by randomly choosing four letters of the full alphabet and excluding any combinations forming pseudowords or partly legal nonwords.

Selection of target and filler items. From the pool of 400 words, 75 words were randomly selected to be used as targets for which priming was measured, and were divided into three sets of 25 items that would appear in each of the three lag conditions. This random selection of targets was different for each subject, ensuring that the pattern of priming observed across lag could not be attributed to item effects and that the pattern reflected properties of priming for the whole pool rather than idiosyncratic properties of only a few words.

The target selection process was repeated for pseudowords, partly legal nonwords, and illegal nonwords. From this procedure, 600 target trials were produced ( 25 targets per condition $\times 3$ lags $\times$ 4 item types $\times 2$ presentations for each target). All target items required a same response (e.g., tape-TAPE, $x y f s-\mathrm{XYFS}$ ) on both presentations.

The remaining 1,300 stimuli ( 400 items per type $\times 4$ item types -300 target items) were put into a single pool, from which 828 items were selected at random for use on filler trials. (The remaining items in the pool were not used for a given subject.) Some fillers (157 trials) required a same response but appeared only once in the list. Most required a different response, and either were repeated ( 376 trials including both presentations) or were not ( 255 trials). With the addition of the fillers, $50 \%$ of all trials in the list required a different response, and the proportion of repeated different trials was the same as the proportion of repeated same trials. 
A final type of filler presented subjects initially with two identical words or nonwords (e.g., tape-TAPE) that required a same response. On the next trial, one of the items was changed so as to require a different response (e.g., tape-BEDL). This condition (40 trials) was used to discourage subjects from responding "same" to target pairs repeated at lag 0 by recognizing the left-hand, or righthand, item alone.

\section{Procedure}

All subjects were tested individually in a single $1.5-\mathrm{h}$ session. A short practice (with five-letter items) was given prior to the actual experiment. Each experimental block took approximately $10 \mathrm{~min}$ to complete, and a short break was given between blocks

Stimuli were presented using PsychLab software on a Macintosh Plus computer, in Geneva 24-point font. A new trial began every 2 sec. The stimulus disappeared from the screen as soon as a response was made, and the screen remained blank for the remainder of the trial. If subjects did not respond within the 2-sec period, the next trial commenced automatically and they were told to ignore the trial they had missed. On a given trial, the pair of letter strings presented appeared simultaneously, with the string on the left of the screen in lowercase and that on the right of the screen in uppercase. Subjects were required to decide whether the two strings had the same identity. (Forcing subjects to compare stimuli across case ensured that they could not simply base their same-different decision on matching the surface features of the items.)

Subjects responded via one of two buttons on the keyboard, using their preferred hand for same responses and the other hand for different responses. The key pressed and the response latency from onset of the item were recorded. Subjects were instructed to respond as quickly and accurately as possible, but no feedback on either accuracy or reaction time was given during the course of the experiment.

\section{Results and Discussion}

Reaction times for same reponses were analyzed as a function of lag and wordlikeness category. Reaction times for word targets were excluded if they were $<250 \mathrm{msec}$ or $>1,200 \mathrm{msec}$. Upper cutoffs were changed to $>1,350 \mathrm{msec}$ for pseudowords, $>1,500 \mathrm{msec}$ for partly legal nonwords, and $>1,650 \mathrm{msec}$ for illegal nonwords because the distribution of reaction times shifted toward higher values in the less wordlike conditions. The outlier cutoffs selected allowed a roughly constant percentage of trials to be excluded in each condition: $2.9 \%$ for words, $1.9 \%$ for pseudowords, $1.8 \%$ for partly legal nonwords, and $3.1 \%$ for illegal nonwords.

Reaction times were also excluded if the response made to the target was incorrect. Error rates in the critical conditions (including errors to either or both presentations) were $5.0 \%$ for words, $3.3 \%$ for pseudowords, $4.3 \%$ for partly legal nonwords, and $6.6 \%$ for illegal nonwords. A $2.9 \%$ error rate was obtained for different trials. Error rates for different trials were not analyzed but served to provide a check on the validity of the same responses by showing that subjects were not just responding "same" to all trials.

\section{First Presentation Reaction Times}

Reaction times to first presentations of targets were analyzed with two aims in mind: first, of confirming that lexical knowledge was used to assist performance on the same-different task, and second, of validating our chosen manipulation of wordlikeness. First presentation reaction times are given in Table 1 as a function of wordlikeness and the lag at which the item would later be repeated.

These data were analyzed initially via a two-way repeated measures analysis of variance (ANOVA). The ANOVA revealed a main effect of wordlikeness $[F(3,45)=$ $\left.56.60, M S_{\mathrm{e}}=5,952, p<.001\right]$, no main effect of future lag $\left[F(2,30)=2.34, M S_{\mathrm{e}}=924, p>.1\right]$, and no interaction between lag and wordlikeness $\left(F<1, M S_{\mathrm{e}}=1,100\right)$. Averaging across lag conditions, mean reaction times were $749 \mathrm{msec}$ for words, $790 \mathrm{msec}$ for pseudowords, $850 \mathrm{msec}$ for partly legal nonwords, and $942 \mathrm{msec}$ for illegal nonwords. Each decrease in the level of wordlikeness led to a significant increase in the time required to recognize that the two items were the same: Pseudowords were matched more slowly than words $[t(15)=9.08, p<.001]$, partly legal nonwords more slowly than pseudowords $[t(15)=$ $6.16, p<.001]$, and illegal nonwords more slowly than partly legal nonwords $[t(15)=6.18, p<.001]$. Thus, first presentation reaction times show that the different stimuli classes differentially activated preexisting representations at "study" in the order assumed, demonstrating the suitability of our task for investigating the role of such representations in producing priming.

\section{Priming Data}

Priming was analyzed in both absolute terms (i.e., change in milliseconds from first presentation) and relative terms (i.e., percentage change from first presentation). This was done because there were large differences in baseline reaction times across different levels of wordlikeness, and it could be argued that there is more room to improve where unprimed processing is most difficult (Snodgrass, 1989). Except where noted, however, relative priming results were the same as those presented for absolute priming.

Figure 1 shows absolute priming as a function of wordlikeness and lag $\left(\mathrm{p}_{\mathrm{abs}}=\mathrm{RT}_{1}-\mathrm{RT}_{2}\right.$, where $\mathrm{RT} \mathrm{T}_{1}$ is the reaction time to an item's first presentation and $\mathrm{RT}_{2}$ is the reaction time to its second). As expected, priming was greatest at lag 0 , decayed rapidly to lag 1 , and more slowly to lag 6 . What is of interest is that this decay of short-term priming was very similar in form across all four levels of wordlikeness.

A two-way repeated measures ANOVA on the data presented in Figure 1 revealed the expected main effect of $\operatorname{lag}\left[F(2,30)=69.91, M S_{\mathrm{e}}=5,195, p<.001\right]$. Collapsing across wordlikeness category, average priming was significantly greater at lag 0 than at lag $1[t(15)=9.31$, $p<.001]$, and at lag 1 than at lag $6[t(15)=4.39, p<$ $.001]$, demonstrating short-term priming at lags 0 and 1 over and above the long-term value presumed to be attained by lag 6 .

There was also a main effect of wordlikeness $[F(3,45)=$ $\left.3.69, M S_{\mathrm{e}}=1,233, p<.02\right]$, although this was in the opposite direction to that predicted by a modification account (69 $\mathrm{msec}$ for words, $75 \mathrm{msec}$ for pseudowords, $73 \mathrm{msec}$ for 
Table 1

Experiment 1: Reaction Times (in Milliseconds) and

Absolute Priming Scores (in Milliseconds) for

same Responses in the Same-Different Task, as a Function of Lag

\begin{tabular}{|c|c|c|c|c|c|c|c|c|}
\hline \multirow[b]{3}{*}{ Lag } & \multicolumn{8}{|c|}{ Wordlikeness Category } \\
\hline & \multicolumn{2}{|c|}{ Word } & \multicolumn{2}{|c|}{ Pseudoword } & \multicolumn{2}{|c|}{ Partly Legal } & \multicolumn{2}{|c|}{ Illegal } \\
\hline & $M$ & $S D$ & $M$ & $S D$ & $M$ & $S D$ & $M$ & $S D$ \\
\hline \multicolumn{9}{|l|}{ Lag 0} \\
\hline $1 \mathrm{st}$ & 742 & 109 & 802 & 116 & 846 & 153 & 947 & 204 \\
\hline 2nd & 602 & 77 & 635 & 92 & 691 & 123 & 772 & 143 \\
\hline $\mathrm{p}_{\mathrm{abs}}$ & 143 & 51 & 168 & 58 & 161 & 61 & 186 & 96 \\
\hline \multicolumn{9}{|l|}{ Lag 1} \\
\hline 1st & 757 & 107 & 787 & 120 & 859 & 147 & 947 & 169 \\
\hline 2nd & 703 & 99 & 738 & 110 & 793 & 137 & 892 & 165 \\
\hline $\mathrm{p}_{\text {abs }}$ & 54 & 31 & 47 & 25 & 68 & 37 & 58 & 48 \\
\hline \multicolumn{9}{|l|}{$\operatorname{Lag} 6$} \\
\hline $1 \mathrm{st}$ & 747 & 99 & 782 & 120 & 845 & 140 & 931 & 195 \\
\hline 2nd & 738 & 98 & 775 & 119 & 817 & 135 & 900 & 179 \\
\hline $\mathrm{p}_{\text {abs }}$ & 11 & 44 & 10 & 35 & 29 & 38 & 26 & 59 \\
\hline
\end{tabular}

Note-First and second presentation means were calculated from all items correctly responded to on that presentation, even if the other presentation was incorrect. Priming scores $\left(\mathrm{p}_{\mathrm{abs}}=1 \mathrm{st}-2 \mathrm{nd}\right)$ were calculated using only items for which both responses were correct.

partly legal nonwords, and $90 \mathrm{msec}$ for illegal nonwords). The fact that less wordlike items showed more priming at all lags can be attributed simply to the fact that these items had slower baselines and thus more room to improve: When priming was recalculated in relative terms $\left(\mathrm{p}_{\mathrm{rel}}=\right.$ $\left.\left[\left(\mathrm{RT}_{1}-\mathrm{RT}_{2}\right) / \mathrm{RT}_{1}\right]\right)$, the main effect of wordlikeness disappeared $(F<1)$.

The key result of the ANOVA was a lack of any interaction between lag and wordlikeness $\left(F \approx 1, M S_{\mathrm{e}}=1,707\right)$. This argues that the pattern of short-term priming was the same for all levels of wordlikeness, consistent with the view that short-term priming relied on the acquisition of novel traces. This conclusion is further strengthened by the fact that the benefit at lag 0 over and above that at lag 6 was not ordered even in any consistent fashion (lag $0-$ lag 6 priming $=132 \mathrm{msec}$ for words, $158 \mathrm{msec}$ for pseudowords, $132 \mathrm{msec}$ for partly legal nonwords, and $160 \mathrm{msec}$ for random letter strings).

\section{Error Analysis}

Error data were the percentage of trials in each condition to which an incorrect different response was made. Analysis of these data demonstrated that the priming observed in reaction times could not be attributed to speedaccuracy tradeoffs. Collapsing over lag, more decision errors were made to first presentations of words $(3.6 \%)$ than to second presentations $(1.5 \%)$. The same pattern occurred for pseudowords $(2.0 \%$ vs. $1.2 \%)$ and for illegal nonwords (6.8\% vs. $5.2 \%$ ), although for partly legal nonwords, slightly fewer errors were made to first presentations ( $3.2 \%$ vs. $4.1 \%)$. Collapsing across item type, the trend across lag was in the direction of fewer secondpresentation errors at shorter lags $(1.3 \%$ at lag $0,3.1 \%$ at lag $1,3.7 \%$ at lag 6). An ANOVA conducted on priming scores for errors indicated no significant effects of lag, wordlikeness, or lag $\times$ wordlikeness (largest $F=2.55$, smallest $p>.09$ ).

\section{Summary}

The same-different task produced clear evidence that words activated preexisting representations most strongly at "study" (i.e., on first presentation) by showing a smooth trend in which more wordlike items were matched as same faster than less wordlike items. This access to preexisting representations, however, had no influence on priming over short lags: Decay patterns were the same for words and all types of nonwords. The null effect of preexperimental

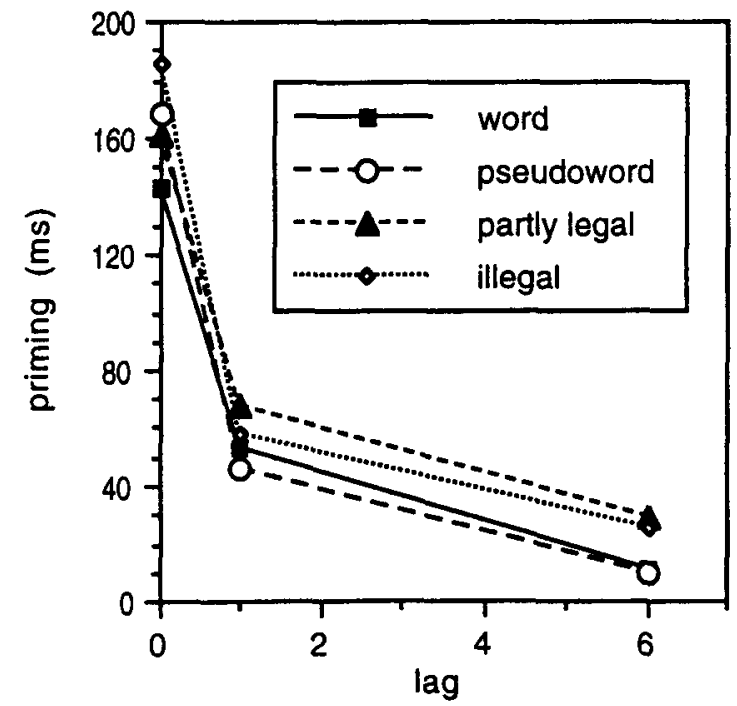

Figure 1. Experiment 1: Repetition priming in the samedifferent across-case comparison task as a function of wordlikeness category and lag between repeats. 
familiarity on short-term priming is particularly convincing given that (1) four levels of wordlikeness were used, spanning a broad range from real English words to completely random letter strings; (2) these four levels gave rise to very different first-presentation reaction times (approximately $200 \mathrm{msec}$ between the extremes); (3) the shortterm priming scores did not vary with wordlikeness in any consistent order; and (4) in our previous studies, we have been able to find highly significant effects using similar numbers of subjects and items per condition.

Our finding of the same decay pattern at all levels of wordlikeness indicates that short-term implicit memory in the same-different task relied on the acquisition of novel traces that included no reference to preexisting representations. Specifically, the stable lexical representations available to real words, and to some extent to pseudowords and partly legal nonwords, gave these items no advantage in priming over completely illegal nonwords. These results are in contrast to those we have reported with lexical decision and naming, where short-term priming for pseudowords was found to decay faster than short-term priming for words.

\section{EXPERIMENT 2}

In Experiment 1, we presented one case in which novelty of the target item did not influence the pattern of shortterm priming. We now report a similar finding based on a different manipulation of preexperimental familiarity, namely the use of old associations (e.g.. apple-orange) and new associations (e.g., cigar-errand). In Experiment 2, priming was compared for each pair type at lags 0,1 , and 6, using a double lexical decision task (Carroll \& Kirsner, 1982). In this task, subjects were presented with the two items simultaneously and required to decide if both were real English words. Only yes responses were of interest; data from trials including nonwords were discarded. (Note that any "familiarity bias" problems with lexical decision do not apply to the present design since priming for no responses was not assessed.)

Of interest is the degree of short-term priming for old and new associations. If such priming relies on preexisting representations, more short-term priming should be found for associated word pairs, for which the "link" between individual items is familiar, than for unassociated word pairs, for which the link between individual items is novel. In contrast, a finding of equal short-term priming for the association regardless of its preexperimental familiarity would show that such priming relied on the acquisition of novel memory traces.

The exact patterns of priming expected are complicated in two ways, both of which arise because individual items are familiar in themselves, and it is only the familiarity of the pairing between the items that is varied. First, if priming relies solely on preexisting representations, considerable short-term priming for new associations would still be expected, given that the left-hand word (e.g., cigar-) and the right-hand word (e.g., -errand) would each produce priming in its own right. Critically, however, the short-term priming for new associations should be less than that for old associations because of the additional contribution made by priming of a familiar link in the latter case.

Second, while the alternative finding of equal shortterm priming for new and old associations would be consistent with the acquisition of novel traces, such a finding is not, in itself, sufficient to demonstrate acquisition of the novel association: It could be that all short-term priming is produced simply by priming of individual items, and that no priming for the association exists for either old or new pairs. Experiment 2 therefore included an additional recombined condition, for old associations at lag 1 only, in which both words of a target pair were primed but their first presentations occurred in different pairs (one at lag 0 , the other at lag 2). If there is priming for the association itself over and above priming for the individual items, then reaction times to second presentations in the ordinary lag 1 condition (in which the pair members were primed together) should be faster than those to second presentations in the recombined condition. ${ }^{5}$

\[ \text { Method } \]
Subjects
Seventeen undergraduate psychology students at the Australian
National University participated, 16 lst-year students who partici-
pated for course credit and 1 later-year volunteer. All subjects re-
ported English as their native language and had normal or cor-
rected-to-normal vision.

\section{Design}

A $2 \times 3$ factorial design was used with association type (new or old) crossed with lag $(0,1$, or 6$)$. Priming effects were measured as the reduction in reaction time, in a double lexical decision task, to the second presentation of a target pair compared with reaction time to the first. Independent of the crossed factorial design, an additional recombined condition was used to provide a baseline against which to assess priming for the "link" for old associations at lag 1. All manipulations were conducted within subjects.

\section{Materials}

Each subject was presented with a different order of lag conditions with minisequences of trials randomized in the same way as was done in Experiment 1. Stimuli were again randomly selected into conditions differently for each subject. The length of the full list was 760 trials, of which 300 were required to present the critical and recombined conditions described below. The full list was split into three presentation blocks containing a maximum of 260 trials each, with the restriction that repeats were not split across blocks.

Critical trials. The associated word pairs were obtained using the Shapiro and Palermo (1968) atlas of normative free association data. Shapiro and Palermo presented a primary stimulus (e.g., white), and subjects were required to respond with an associated word (e.g., black). The probability of coming up with a particular associated word was then determined. For the present experiment, 80 old associations (e.g., orange-apple) were selected that had associative probabilities of at least .70 . Words on the left of each pair had a mean letter length of $5.1(S D=1.6)$ and a mean word frequency of $53(S D=55)$. Words on the right had a mean letter length of $4.9(S D=1.2)$ and a mean word frequency of $58(S D=67)$. A separate list of 80 unassociated word pairs (e.g., cigar-errand) was constructed, which matched the old associations on both word length and word frequency. 
Table 2

Example of a Minisequence of Trials Used in the Recombined Condition of Experiment 2

\begin{tabular}{cll}
\hline Trial in Sequence & Stimulus Pair & \multicolumn{1}{c}{ Purpose of Trial } \\
\hline 1 & apple-house & primes one target (apple) \\
2 & dream-mave & filler trial, gives mean lag=1 \\
3 & dog-orange & primes other target (orange) \\
4 & apple-orange & tests both targets together \\
\hline
\end{tabular}

From the pool of 80 associated word pairs, 60 target pairs were randomly selected and divided into three sets, allowing 20 target pairs in each of the three lag conditions. (Owing to a programming error, 2 subjects received only 19 target items in one lag condition.) This random selection process was different for each subject. The selection of targets and division into lag conditions was repeated for the unassociated word pairs from the pool of 80 such pairs. All target pairs were repeated and required a yes response (i.e., both were real English words). From this procedure, a total of 240 target trials were produced ( 60 pairs $\times 2$ pair types $\times 2$ presentations).

Recombined condition. For old associations at lag 1 , an additional condition was used to allow a measure of the amount of priming for the association between words in a pair, over and above priming for the individual words. Items for this recombined condition were selected from the remaining 20 pairs left in the associated word pair list. A minisequence of four trials was necessary to repeat individual items in this condition at an average of lag 1 , as demonstrated in Table 2. Initially, one word of the target pair was presented in its final left-right position, but was paired with a filler item (left and right target words were selected equally often to be primed first). On the next trial, both items were fillers. The third trial in the sequence primed the other target word by presenting it in its final position, but again paired with a filler. The final trial presented the target pair together; reaction times to this trial were of interest.

Filler trials. Fifty percent of all trials were fillers requiring a no response in the double lexical decision task. These included wordnonword pairings (100 pairs, e.g., house-nable), nonwordword pairings ( 100 pairs, e.g., bain-trunk), and nonword-nonword pairings ( 180 pairs, e.g., bethy-grome). Some of these no pairs were repeated (160 trials), and others were not (220 trials). Additional (unrelated) fillers requiring a yes response were included and presented only once ( 80 trials). As in Experiment 1, the proportion of repeated no trials was such that there was no confounding between repetition and the response required.

\section{Procedure}

The procedure was generally the same as that used for Experiment 1 , with the following differences. Subjects required only a $1-\mathrm{h}$ session to complete three blocks of trials, each of approximately 10min duration. Each pair of items was presented simultaneously in lowercase, and a new trial began every $2.6 \mathrm{sec}$ (a slower presentation rate was allowed than in Experiment 1 due to the expected increased difficulty of the double lexical decision task). Subjects responded via the keyboard with their preferred hand for yes responses (the pair of items were both real English words), and the other hand for no responses (one or both of the items were nonwords).

On completion of the computer task, subjects were required to rate the degree of association between each of the critical word pairs selected for the experiment. Ratings were made on a 5-point scale ( 1 = extremely associated $5=$ not at all associated $)$.

\section{Results and Discussion}

Subjects rated the old associations to be very strongly related $(M=1.3, S D=0.6)$ and the new associations to be very weakly related $(M=4.4, S D=1.0)$, providing a basic validation of our selection of items. The primary data of interest were then lexical decision times to target pairs as a function of lag. Reaction times were excluded from analysis if they were $<250 \mathrm{msec}$ or $>1,300 \mathrm{msec}$ for associated word pairs ( $1.4 \%$ of the data), and if they were $<250 \mathrm{msec}$ or $>1,400 \mathrm{msec}$ for unassociated word pairs ( $2.1 \%$ of the data). Reaction times were also excluded if the response was incorrect. The data of 1 subject were deleted from the analysis due to an excessive number of errors $(>25 \%)$. Error rates to either or both presentations for the remaining 16 subjects were $2.7 \%$ for associated word pairs and $4.8 \%$ for unassociated word pairs. An acceptable error rate of $7.4 \%$ was obtained for trials requiring a no response, indicating that reaction times to yes responses could validly be analyzed.

\section{First-Presentation Times}

First-presentation reaction times (Table 3) confirmed that old associations activated a preexisting representation at study, with lexical decisions to old association pairs $(778 \mathrm{msec})$ considerably faster than those to new associations ( $853 \mathrm{msec})$. A two-way repeated measures ANOVA revealed the main effect of association type $[F(1,15)=$ $51.7, M S_{\mathrm{e}}=2,632, p<.001$ ], but no main effect of lag of the future repetition $\left(F<1, M S_{\mathrm{e}}=1,050\right)$, and no interaction between lag and pair type $\left[F(2,30)=1.2, M S_{\mathrm{e}}=\right.$ $1,458, p>.2]$.

\section{Priming Data}

Figure 2 shows repetition priming measured as the absolute increase in speed of response to second presentations (i.e., $\mathrm{p}_{\mathrm{abs}}=\mathrm{RT}_{1}-\mathrm{RT}_{2}$ ) as a function of association type and lag. The most relevant aspect of the data is the similarity in the decay patterns of priming for new and old associations.

A two-way repeated measures ANOVA revealed the expected main effect of lag $\left[F(2,30)=71.68, M S_{\mathrm{e}}=2,625\right.$, $p<.001]$, although a somewhat surprising finding was

Table 3

Experiment 2: Reaction Times (in Milliseconds) and Absolute Priming Scores ( $\mathrm{p}_{\text {abs }}$ in Milliseconds) for yes Responses in the Double Lexical Decision Task as a Function of Lag

\begin{tabular}{crrrr} 
& \multicolumn{4}{c}{ Association Type } \\
\cline { 2 - 5 } Lag & \multicolumn{2}{c}{ Old } & & New \\
\cline { 2 - 3 } \cline { 4 - 5 } Lag 0 & & $S D$ & & $S D$ \\
1st & 781 & 80 & 849 & 128 \\
2nd & 603 & 78 & 627 & 97 \\
$\mathrm{p}_{\text {abs }}$ & 176 & 55 & 224 & 90 \\
Lag 1 & & & & \\
1st & 782 & 71 & 847 & 97 \\
2nd & 711 & 89 & 773 & 103 \\
$\mathrm{p}_{\text {abs }}$ & 73 & 46 & 79 & 62 \\
Lag 6 & & & & \\
1st & 771 & 113 & 864 & 113 \\
2nd & 723 & 101 & 799 & 101 \\
$\mathrm{p}_{\text {abs }}$ & 52 & 63 & 68 & 63 \\
\hline
\end{tabular}

Note--Means were calculated as described in Table 1 for Experiment 1. 




Figure 2. Experiment 2: Repetition priming in the double lexical decision task as a function of association type and lag.

the little, if any, short-term priming at lag 1. Collapsing across association type, priming at lag 0 was significantly greater than priming at lag $1[t(15)=10.22, p<.001]$, but lag 1 priming did not differ significantly from that at lag $6[t(15)=1.56, p>.1]$. One reason for this might simply be a lack of power to detect a small but real shortterm priming effect (priming at lag 1 was greater than that at lag 6 by $16 \mathrm{msec}$ ), but factors of more theoretical interest include the relatively slow presententation rate $(2.6 \mathrm{sec}$ per trial) and the fact that two items were presented for lexical decision on each trial, so that lag 1 in terms of trials equaled lag 2 in terms of distinct items. McKone (1998) has demonstrated that short-term priming decays via both time delay and interference from intervening items, making it plausible that lag 1 priming might be relatively small in the double lexical decision task.

The ANOVA also revealed a main effect of association type $\left[F(1,15)=8.50, M S_{\mathrm{e}}=1,505, p<.02\right]$, although, as in Experiment 1, this was in the opposite direction to that predicted by a modification account $(99 \mathrm{msec}$ for old associations vs. $114 \mathrm{msec}$ for new associations). Again, the main effect of familiarity disappeared when priming was recalculated in relative terms $\left[F(1,15)=2.5, M S_{\mathrm{e}}=18.73\right.$, $p>.1$, suggesting that it could be attributed simply to baseline differences.

The most important finding of the ANOVA was no significant interaction between association type and lag $\left[F(2,30)=1.41, M S_{\mathrm{e}}=2,695, p>.2\right]$. Further, the amount of priming at lag 0 over and above priming at lag 6 was similar for old (124 msec) and new (156 msec) associations. Thus, short-term priming took the same form for new associations as for old associations.

\section{Recombined Condition}

The six basic lag $\times$ association type conditions revealed equivalent patterns of short-term priming for new and old associations. This is consistent with an acquisition account of short-term priming, but is also open to an alternative interpretation: Priming for both new and old associations might be entirely attributable to repetition of individual items and thus say nothing about the role of a familiar or novel link between pairs of items.

To address this possibility, we analyzed data from the recombined condition. Reaction times to second presentations in this condition (where the pair members had been previously primed in different pairs) were compared with reaction times to second presentations of old associations at lag 1 (where the pair members had been previously primed in the same pair). This comparison revealed a nonsignificant priming effect of only $5 \mathrm{msec}$ for the link between pair members, with mean reaction times of $716 \mathrm{msec}$ for different pairs and $711 \mathrm{msec}$ for same pairs $[t(15)=0.34, p>.2]$.

This finding suggests that there was no significant priming for the link between associated word pairs at lag 1, and thus that all lag 1 priming could be attributed to priming of individual items. However, given that no significant short-term priming was actually observed at lag 1 , this conclusion in fact tells us little about priming for the link in short-term implicit memory (5-msec priming for the link is not that small a proportion of the total of 16msec short-term priming at lag 1). Lag 0 was the only lag at which priming was clearly above the long-term value, and Experiment 2 included no way of assessing priming for particular pairings (as opposed to individual items) at this lag. Therefore, we cannot say whether the results necessarily imply that acquisition of novel traces was responsible for producing short-term priming.

\section{Error Data}

Error data were the percentage of trials to which an incorrect no response was made and showed no evidence of speed-accuracy tradeoffs. Collapsing over lags $0-6$, more decision errors were made to first presentations than to second presentations, for both old associations $(1.9 \%$ vs. $1.3 \%)$ and new associations $(5.3 \%$ vs. $2.2 \%)$. Collapsing across item type, the trend across lag was for fewer second-presentation errors at lag $0(0.3 \%)$ than at lag $1(2.7 \%)$ or lag $6(2.2 \%)$. A two-way ANOVA on priming scores revealed no effect of $\operatorname{lag}\left[F(2,30)=2.07, M S_{\mathrm{e}}=\right.$ $18.55, p>.1]$ and no interaction with association type $\left(F<1, M S_{\mathrm{e}}=31.21\right)$. A main effect of association type was revealed $\left[F(1,15)=4.52, M S_{\mathrm{e}}=33.38, p<.05\right]$, but again this reflected a finding that new associations showed more priming than old associations, presumably reflecting the higher baseline error rates to these pairs.

\section{Summary}

Equivalent patterns of priming across lag were found for new and old associations, with significant short-term priming apparent only at lag 0 for both pair types. The null effect on short-term priming of preexperimental familiarity is strengthened by two aspects of the data: (1) Firstpresentation reaction times differed substantially between the two pair types (by approximately $70 \mathrm{msec}$ ), and (2) the 
priming scores at lag 0 were ordered in the wrong direction to be explained as arising from activation of preexisting representations (i.e., new associations showed a trend toward more priming than did old associations). These data are consistent with the view that priming relied on acquisition of novel traces. However, the lack of any way of assessing priming for the link between paired items at lag 0 leaves open the possibility that all short-term priming arose simply from the repetition of individual items. Experiment 3, therefore, aimed to show that at least some of the lag 0 priming found in Experiment 2 was attributable to the associative relationship between the items.

\section{EXPERIMENT 3}

Experiment 3 further examined priming for old and new associations in a double lexical decision task, but specifically evaluated the existence or otherwise of priming for the associative relation between pair members at lag 0 . If priming for particular pairings (over and above individual items) can be established using the same stimuli as those in Experiment 2, then the results of the two experiments in combination would provide strong evidence that acquisition of a new trace of an unfamiliar association was responsible for short-term priming.

In Experiment 3, four priming conditions were compared, for both old and new associations. These were the baseline condition, in which neither item of the target pair was primed, the left-primed condition, in which the item appearing on the left was repeated, the right-primed condition, in which the item appearing on the right was repeated, and the both-primed condition, in which both items were repeated. Lexical decision times to target pairs in each of the three primed conditions were compared, in turn, with those in the baseline condition to calculate priming. For example, the advantage arising from repetition of the left item alone was calculated by subtracting reaction times in the left-primed condition from those in the baseline condition (i.e., $\mathrm{p}_{\text {left }}=\mathrm{RT}_{\text {baseline }}-\mathrm{RT}_{\text {left-primed }}$ ).

If all priming at lag 0 in the double lexical decision task is attributable to priming for individual items, then the repetition advantage when both items are repeated together should simply be the sum of the advantages due to repeating each item individually. That is, we should find $\mathrm{p}_{\text {both }}=$ $\mathrm{p}_{\text {left }}+\mathrm{p}_{\text {right }}$. If, on the other hand, lag 0 priming for the association exists over and above priming for individual items, then we should find $p_{\text {both }}>p_{\text {left }}+p_{\text {right. It is the }}$ latter result that must be found to make the results of Experiment 2 interpretable as unambiguous evidence for the novel traces of unfamiliar associations.

\section{Method}

\section{Subjects}

Twenty-one subjects participated in all. Of these, 16 were $1 \mathrm{st}-$ year students at the Australian National University who participated for course credit, 4 were later-year students who were paid $\$ 10$ for the 1-h session, and 1 was a volunteer from the Australian National University community.

\section{Design}

A $4 \times 2$ repeated measures factorial design was employed, with priming condition (baseline, left-primed, right-primed, or bothprimed) crossed with association type (new or old). The primary dependent variable was reaction time in a double lexical decision task.

\section{Materials}

Each priming condition required a minisequence of two trials. In the left-primed condition, the target pair was preceded by a trial containing the left-hand target word, but the right-hand target was replaced by a filler. In the right-primed condition, the preceding trial contained the right-hand target word but the left-hand target was replaced by a filler. In the both-primed condition, the preceding trial contained both targets in their final positions. All target pairs required a yes response, as did first presentations in all priming conditions. Note that first presentations formed unrelated pairs in all except the both-primed condition for old associations. This was necessary because of the restricted number of related pairs available.

Each subject was presented with a different order of conditions, with minisequences of trials randomized in the same way as was done in Experiments 1 and 2. A total of 720 trials were presented in three blocks containing a maximum of 260 trials each.

The pool of 80 critical old associations and 80 critical new associations selected for Experiment 2 was used again in Experiment 3. This allowed 20 target pairs to be presented in each of the four priming conditions. Items were randomly selected into conditions differently for each subject. Thus, each subject saw a given target pair in one condition only, and item-specific effects were again avoided by collapsing data across subjects.

To make the lag structure of the full list reasonably similar to that used in Experiment 2, 20 additional yes filler trials were repeated at lags $1,2,3$, and 4 . The only yes trials that remained completely unrepeated (i.e., neither item appeared on any later trial) were the 40 first presentations of the baseline conditions. As much as possible, a confounding of repetition and response was avoided by including only 50 unrepeated no trials. All other no trials were repeated (with both items repeated together), most commonly at lag 0 and less frequently at lags 1,2 , and 3 . Of the full list, $50 \%$ of trials required a no response. Thirty fewer filler trials were presented than in Experiment 2, but these fillers were selected at random for each subject from the full pool previously used.

\section{Procedure}

The procedure was identical to that employed for Experiment 2, with the exception that the rating scale was not administered.

\section{Reaction Time Data}

\section{Results and Discussion}

Individual reaction times were excluded from analysis if the response to either the first or the second presentation was incorrect, and data from 3 subjects were discarded completely because of excessive error rates $(>10 \%$ for both yes and no responses). Average error rates for the remaining 18 subjects were $3.5 \%$ for yes responses and $6.4 \%$ for no responses. Reaction times were also excluded as outliers if they were $<300 \mathrm{msec}$ or $>1,400 \mathrm{msec}$, removing $2.8 \%$ of the data in the old association conditions and $1.8 \%$ of the data in the new association conditions. A common upper cutoff was used for both associ- 
Table 4

Experiment 3: Reaction Times (in Milliseconds) and Absolute Priming Scores ( $p_{\text {abs }}$, in Milliseconds) at Lag 0 for yes Responses in the Double Lexical Decision Task

\begin{tabular}{|c|c|c|c|c|c|}
\hline \multirow{2}{*}{$\begin{array}{c}\text { Association } \\
\text { Type }\end{array}$} & \multirow{2}{*}{$\begin{array}{l}\text { Priming } \\
\text { Condition }\end{array}$} & \multicolumn{2}{|c|}{ Reaction Time } & \multicolumn{2}{|c|}{$\mathrm{p}_{\mathrm{abs}}$} \\
\hline & & $M$ & $S D$ & $M$ & $S D$ \\
\hline \multirow[t]{4}{*}{$\overline{\text { Old }}$} & Baseline & 727 & 75 & - & - \\
\hline & Left-primed & 694 & 65 & 34 & 52 \\
\hline & Right-primed & 691 & 59 & 37 & 50 \\
\hline & Both-primed & 609 & 46 & 118 & 53 \\
\hline \multirow[t]{4}{*}{ New } & Baseline & 785 & 81 & $\ldots$ & - \\
\hline & Left-primed & 726 & 80 & 59 & 50 \\
\hline & Right-primed & 737 & 70 & 49 & 49 \\
\hline & Both-primed & 643 & 66 & 142 & 68 \\
\hline
\end{tabular}

Note-Priming scores in the left-, right-, and both-primed conditions were calculated as differences from the relevant baseline value, as described in the text.

ation types since first presentations of the target old associations formed unrelated pairs except in the bothprimed condition.

Table 4 presents the mean lexical decision times to target pairs in each priming condition for new and old associations. Across all conditions, new associations were identified as words some $40 \mathrm{msec}$ more slowly than old associations. A $4 \times 2$ ANOVA conducted on the priming condition $X$ association type data revealed this main effect of association type to be significant $[F(1,17)=67.70$, $\left.M S_{\mathrm{e}}=962.3, p<.001\right]$. The ANOVA also showed a significant main effect of priming condition $[F(3,51)=63.10$, $\left.M S_{\mathrm{e}}=1,697, p<.001\right]$, with responses slowest in the baseline conditions and fastest in the both-primed conditions, as expected. There was no significant interaction between priming condition and association type $[F(3,51)=1.59$, $\left.M S_{\mathrm{e}}=810.0, p>.2\right]$, indicating that priming patterns were similar for old and new associations. This similarity of pattern was confirmed when the existence or otherwise of priming for the association between items was examined for each pair type.

\section{Priming for Individual Items and the Association Between Items}

Absolute priming in the left-primed, right-primed, and both-primed conditions is shown in Table 4, calculated with respect to the relevant baseline condition; for example, priming for the left-primed condition was calculated as $\mathrm{p}_{\text {abs }}=\mathrm{RT}_{\text {left-primed }}-\mathrm{RT}_{\text {baseline. }}$. Analysis of relative priming scores exactly replicated that for the absolute priming data.

Responses to old associations were primed to a substantial extent by repetition of the left item alone $\left(\mathrm{p}_{\text {left }}=\right.$ $34 \mathrm{msec})$ or of the right item alone $\left(\mathrm{p}_{\text {right }}=37 \mathrm{msec}\right)$. Of most interest, however, was that the priming observed when both items were repeated could not simply be attributed to the sum of these individual item effects: $p_{\text {both }}$ was $118 \mathrm{msec}$, while the sum of $\mathrm{p}_{\text {left }}$ and $\mathrm{p}_{\text {right }}$ was only $70 \mathrm{msec}$. These values differed significantly $[t(17)=3.46$, $p<.01$ ], leaving $48 \mathrm{msec}$ of priming attributable to rep- etition of the old association. For new associations, the same pattern emerged. There was substantial priming from repetition of the left $(59 \mathrm{msec})$ and right $(49 \mathrm{msec})$ items individually. Again, however, $\mathrm{p}_{\text {both }}$ at $142 \mathrm{msec}$ was significantly greater than the sum of $\mathrm{p}_{\text {left }}$ and $\mathrm{p}_{\text {right }}$ at $107 \mathrm{msec}$ $[t(17)=2.13, p<.05]$, leaving $35 \mathrm{msec}$ of priming attributable to repetition of the new association. Thus, at lag 0 , priming of the association between pair members was observed for both pair types, at similar levels (48 vs. $35 \mathrm{msec}$ ).

\section{Error Data}

There were no speed-accuracy tradeoffs. Overall error rates were similar for old $(3.5 \%)$ and new $(3.7 \%)$ associations. Collapsed across association type, most errors occurred in the baseline condition $(4.4 \%)$, fewer in the leftprimed (3.7\%) and right-primed (3.6\%) conditions, and least in the both-primed $(2.8 \%)$ condition, although the priming effects on errors were not significant. A $4 \times 2$ ANOVA showed no main effect of association type $(F<$ $\left.1, M S_{\mathrm{e}}=12.90\right)$, no differences among priming conditions $\left[F(3,60)=1.72, M S_{\mathrm{e}}=11.36, p>.1\right]$, and no interaction $[$ Wilks' Lambda $=.724, F(3,18)=2.29, p>.1] .{ }^{6}$

\section{Summary}

Experiment 3 confirmed that a significant proportion of the total priming in the double lexical decision task at lag 0 was attributable to priming of the association, or link, between pair members. This finding clarifies the interpretation of data obtained in Experiment 2. In that experiment, equivalent decay patterns over lag were observed for new and old associations, but it was possible that all priming could be attributed simply to repetition of individual items. The present results remove this ambiguity and demonstrate that short-term priming did occur for a previously seen pairing, regardless of whether a preexisting representation of that pairing existed in memory. Even more strongly, the present experiment showed similar levels of priming for the link in new and old associations. Thus, Experiments 2 and 3 together provide convincing evidence that short-term priming for pairs relies on acquisition of a novel memory trace, rather than modification of preexisting knowledge.

\section{GENERAL DISCUSSION}

In the three experiments reported here, we have presented two cases where short-term implicit memory relied on novel memory traces including no reference to preexisting representations. The two cases described used different manipulations of preexperimental familiarity and, in both, short-term priming was found to be as strong for novel items as for familiar items.

In Experiment 1, we varied the similarity of four-letter strings to valid English orthography by using real words, highly wordlike pseudowords, partly legal nonwords, and random letter strings as stimuli. When subjects were asked to make same-different judgments to lowercase-uppercase 
pairs, the initial magnitude and the decay rate of shortterm priming were the same for all classes of stimuli. This null effect on priming was obtained in the context of direct evidence that, on first presentation, preexisting knowledge about the structure of English was accessed in performing the task. The results show that priming was unaffected by the degree to which a preexisting representation was activated and are particularly convincing in that illegal letter strings showed the same priming pattern as all other items: Although it can be argued that pseudowords activate preexisting representations by virtue of their familiar sublexical components (Seidenberg \& McClelland, 1989; Taft, 1991), this argument cannot be extended to random letter strings.

In Experiments 2 and 3, we varied the familiarity of the association between two real words and used a double lexical decision task to examine priming. The magnitude and decay rate of short-term priming were the same for both old and new associations in Experiment 2, and it was demonstrated in Experiment 3 that at least some of the initial (lag 0 ) priming could be attributed to the association itself, over and above the contributions of priming from individual words in the pair. Again, these data indicate acquisition of novel traces, given that the presence or otherwise of a preexisting representation (in this case of the association) had no influence on short-term priming.

The results reported in this article demonstrate that novel memory traces can underlie short-term priming, at least under some circumstances. With the two experimental paradigms we employed here, preexperimental familiarity of the stimulus did not contribute in any way to short-term priming. It should be noted, however, that the patterns of priming reported in McKone $(1995,1998)$ and McKone and Dennis (1998) suggest, in contrast, that activation of preexisting representations plays a crucial role in producing short-term priming. In those studies, items were presented one at a time for lexical decision or naming, and (with visual presentation) priming for pseudowords decayed much more rapidly than priming for words. This interaction between lag and lexical status was used to argue that transient activation of preexisting lexical knowledge was responsible for short-term priming, and all theoretical discussion of short-term priming was cast in this framework.

Given the conflict in results between these papers and the present work, it appears that short-term implicit memory may rely on acquisition of novel traces (with no role for preexisting knowledge) under some circumstances and on modification of old representations under others. This conclusion is perhaps unsurprising, if the extensive literature is considered on the role of abstract preexisting representations versus episode-specific novel traces in long-term implicit memory. Tenpenny's (1995) recent review covers more than 10 years of research on this topic and demonstrates that the question has no simple one-orthe-other answer. Conflicting data support both the view that long-term priming involves reference to preexisting representations (e.g., Dorfman, 1994; Musen \& Squire,
1993; Reingold \& Goshen-Gottstein, 1996) and the view that long-term priming relies on acquisition of completely novel traces (e.g., Bowers, 1994; Graf \& Schacter, 1985; Roediger \& Blaxton, 1987).

In explaining long-term priming, some researchers (e.g., Brown \& Carr, 1993, p. 1278; Carr \& Brown, 1990; Logan, 1988, p. 495; Logan, 1990) have argued that the relative contribution of each mechanism changes with different experimental demands. Logan (1990) has proposed that novel memory traces underlie all long-term priming, but that the content of a trace can vary depending on the interpretation of the stimulus determined by the task performed. For example, deciding whether a stimulus is handwritten or typewritten would leave a trace primarily of the appearance of the stimulus with little reference to its familiarity status, whereas deciding whether or not a stimulus makes a real word would leave a trace that emphasizes whether or not the item has a preexisting representation. Under this view, priming in a task emphasizing lower level properties of the stimulus might be as strong for novel items as for items that are preexperimentally familiar, whereas priming in a higher level task' should be strongly dependent on preexisting representations.

To return to short-term priming, a possible interpretation of the conflicting effects of preexperimental familiarity in different tasks would be to propose, as Logan (1990) has for long-term priming, that the types of traces underlying short-term priming can vary depending on the goals of the task. The lexical decision and naming tasks used in McKone $(1995,1998)$ and McKone and Dennis (1998) require integrating all letters of the stimulus into a whole and determining whether or not this whole exists in the lexicon; in these tasks, then, a task goals analysis would predict the observed finding that priming relies on preexisting representations. In each case reported in the present article, in contrast, it could be argued that the task focused attention at the level immediately below that at which the preexisting representation is relevant. In Experiment 1, the preexisting representation under consideration was that of whole words (i.e., words were contrasted with various types of nonwords), but the goal of the task was focused at the level of single letters (i.e., subjects were required to match strings of letters across case). In Experiments 2 and 3, the preexisting representation under consideration was the association betweeen pairs of words familiar in their own right (i.e., familiar associations were contrasted with novel associations), but the goal of the task was focused at the level of single words and made no direct reference to the pairing (i.e., subjects were asked to make lexical decisions). Again, a task goals analysis could be used to predict the finding that preexisting representations did not contribute to priming under these circumstances.

If our interpetation is correct, preexisting representations should contribute to short-term priming only when the level of the task matches the level at which the existence of the preexisting representation is relevant. We have some further unpublished data from our laboratory that 
are consistent with this view. Using a task in which subjects were required to search for a single letter in a word or nonword (respond "present" if the letter occurred in a fourletter target string, "absent" otherwise; all primed trials required a present response), patterns of short-term priming were found to match those reported in Experiment 1 of the present paper; that is, short-term priming was as strong for random letter strings as for real words. When the task was changed to lexical decision, the results were consistent with those of McKone (1995): Short-term priming was weaker for pseudowords than for real words, and was much weaker still for random letter strings.

More data will be needed before the role that preexisting representations play in producing short-term implicit memory under various circumstances can be fully determined. There are many factors that might influence the relative contributions of novel traces and old knowledge to short-term priming, and, at this stage, it may be premature to expect a simple resolution of our conflicting results regarding the role of preexperimental familiarity in such priming. The contribution of the present work is to show that short-term priming can, under some circumstances at least, rely on the acquisition of novel memory traces that include no reference to preexisting representations. Despite the fact that the duration of short-term priming makes it an obvious candidate for an effect produced by a simple activation mechanism, we have shown that a modification account is not sufficient to explain all the data.

\section{REFERENCES}

BADDELEY, A. D. (1990). Human memory: Theory and practice. Needham Heights, MA: Allyn \& Bacon.

BOWERS, J. S. (1994). Does implicit memory extend to legal and illegal nonwords? Journal of Experimental Psychology: Learning, Memory, \& Cognition, 20, 534-549.

Brown, J. S., \& CARR, T. H. (1993). Limits on perceptual abstraction in reading: Asymmetric transfer between surface for msec differing in typicality. Journal of Experimental Psychology: Learning, Memory, \& Cognition, 19, 1277-1296.

Carr, T. H., \& Brown, J. S. (1990). Perceptual abstraction and interactivity in repeated oral reading: Where do things stand? Journal of Experimental Psychology: Learning. Memory, \& Cognition, 16, 731 738.

Carroll, M., \& Kirsner, K. (1982). Context and repetition effects in lexical decision and recognition memory. Journal of Verbal Learning \& Verbal Behavior, 21, 55-69.

Cermak, L. S., Talbot, N., Chandler, K., \& Wolbart, L. R. (1985). The perceptual priming phenomenon in amnesia. Neuropsychologia, 23, 615-622.

Coltheart, M., Davelaar, E., Jonasson, J. T., \& Besner, D. (1977). Access to the internal lexicon. In S. Dornic (Ed.), Attention and performance VI (pp. 535-555). Hillsdale, NJ: Erlbaum.

Diamond, R., \& Rozin, P. (1984). Activation of existing memories in anterograde amnesia. Journal of Abnormal Psychology, 93, 98-105.

Dorfman, J. (1994). Sublexical components in implicit memory for novel words. Journal of Experimental Psychology: Learning, Memory, \& Cognition, 20, 1108-1125.

Feustel, T. C., Shiffrin, R. M., \& Salasoo, A. (1983). Episodic and lexical contributions to the repetition effect in word identification. Journal of Experimental Psychology: General, 112, 309-346.

ForSTER, K. I. (1976). Accessing the mental lexicon. In R. J. Wales \& E. Walker (Eds.), New approaches to language mechanisms (pp. 257287). Amsterdam: North-Holland.

Graf, P., \& MANDLER, G. (1984). Activation makes words more acces- sible, but not necessarily more retrievable. Journal of Verbal Learning \& Verbal Behavior, 23, 553-568

GRAF, P., \& SCHACTER, D. L. (1985). Implicit and explicit memory for new associations in normal and amnesic subjects. Journal of Experimental Psychology: Learning, Memory, \& Cognition, 11, 501-518.

Grossberg, S. (1980). How does the brain build a cognitive code? Psychological Review, 87, 1-51.

JACOBY, L. L. (1983). Remembering the data: Analyzing interactive processes in reading. Journal of Verbal Learning \& Verbal Behavior, 22, 485-508.

KIRSNER, K., \& SMITH, M. C. (1974). Modality effects in word identification. Memory \& Cognition, 2, 637-640.

KUČERA, M., \& FRANCIS, W. (1967). Computational analysis of present day American English. Providence, RI: Brown University Press.

LoGAN, G. D. (1988). Toward an instance theory of automatization. Psychological Review, 95, 492-527.

LoGAN, G. D. (1990). Repetition priming and automaticity: Common underlying mechanisms? Cognitive Psychology, 22, 1-35.

Maljkovic, V., \& Nakayama, K. (1994). Priming of pop-out: I. Role of features. Memory \& Cognition, 22, 657-672.

MalJKovic, V., \& NaKaYAma, K. (1998). Priming of pop-out: III. A short term implicit memory system beneficial for rapid target selection. Manuscript submitted for publication.

MCClelland, J. L., \& Rumelhart, D. E. (1981). An interactive activation model of context effects in letter perception: Part 1. An account of basic findings. Psychological Review, 88, 375-407.

MCClelland, J. L., \& RUMElHaRT, D. E. (1988). Explorations in parallel distributed processing: $A$ handbook of models, programs and excercises. Cambridge, MA: MIT Press.

MCKONE, E. (1995). Short-term implicit memory for words and nonwords. Journal of Experimental Psychology: Learning, Memory, \& Cognition, 21, $1108-1126$.

MCKONE, E. (1998). The decay of short-term implicit memory: Unpacking lag. Memory \& Cognition, 26, 1173-1186.

McKone, E., \& DeNNIS, C. (1998). Short-term implicit memory: Auditory and cross-modality priming. Manuscript submitted for publication.

McKoon, G., \& RatclifF, R. (1979). Priming in episodic and semantic memory. Journal of Verbal Learning \& Verbal Behavior, 18, 463-480.

Morris, C. D., BranSFord, J. D., \& FranKS, J. J. (1977). Levels of processing versus transfer appropriate processing. Journal of Verbal Learning \& Verbal Behavior, 16, 519-533.

MORTON, J. (1969). Interaction of information in word recognition. Psychological Review, 76, 165-178.

Musen, G., \& Souire, L. R. (1993). On the implicit learning of novel associations by amnesic patients and normal subjects. Neuropsychology, 7, 119-135.

Patterson, K. E., \& Morton, J. (1985). From orthography to phonology: An attempt at an old interpretation. In K. E. Patterson, J. C. Marshall, \& M. Coltheart (Eds.), Surface dyslexia (pp. 335-359). London: Erlbaum.

Reicher, G. M. (1969). Perceptual recognition as a function of meaningfulness of stimulus material. Journal of Experimental Psychology, 81, 275-280

Reingold, E. M., \& Goshen-Gottstein, Y. (1996). Separating consciously controlled and automatic influences in memory for new associations. Journal of Experimental Psychology: Learning, Memory, \& Cognition, 22, 397-406.

RichaRdSON-KLAVEHN, A., \& BJoRK, R. A. (1988). Measures of memory. Annual Review of Psychology, 39, 475-543.

RoEDIGER, H. L., III (1990). Implicit memory: Retention without remembering. American Psychologist, 45, 1043-1056.

RoEdiger, H. L., III, \& BLAXTON, T. A. (1987). Effects of varying modality, surface features, and retention interval on priming in wordfragment completion. Memory \& Cognition, 15, 379-388.

ROEDIGER, H. L., III, \& MCDERMOTT, K. B. (1993). Implicit memory in normal human subjects. In F. Boller \& J. Grafman (Eds.), Handbook of neuropsychology (Vol. 8, pp. 63-131). Amsterdam: Elsevier.

Scarborough, D. L., Cortese, C., \& Scarborough, H. S. (1977). Frequency and repetition effects in lexical memory. Journal of Experimental Psychology: Human Perception \& Performance, 3, 1-17. SCHACTER, D. L. (1987). Implicit memory: History and current status. 
Journal of Experimental Psychology: Learning, Memory, \& Cognition, 13, 501-518.

Seidenberg, M. S., \& MCClelland, J. L. (1989). A distributed, developmental model of word recognition and naming. Psychological Review, 96, 523-568.

Shapiro, S. I., \& Palermo, D. S. (1968). An atlas of normative free association data. Psychonomic Monograph Supplements, 2 (12, whole No. 28), 219-250.

SNoDGRaSs, J. G. (1989). Sources of learning in the picture fragment completion task. In S. Lewandowsky, J. C. Dunn, \& K. Kirsner (Eds.), Implicit memory: Theoretical issues (pp. 259-282). Hillsdale, NJ: Erlbaum.

TAFT, M. (1991). Reading and the mental lexicon. London: Erlbaum.

TENPENNY, P. L. (1995). Abstractionist versus episodic theories of repetition priming and word identification. Psychonomic Bulletin \& Review, 2, 339-363.

WheELer, D. D. (1970). Processes in word recognition. Cognitive Psychology, 1, 59-85.

\section{NOTES}

1. Nonword refers to any letter string not forming a real word. Pseudoword refers to nonwords satisfying the orthographic and phonological rules of English.

2. As a possible mechanism phrased in terms of current views of distributed memory storage, it could be proposed that short-term priming results from rapidly decaying unit activations, whereas long-term priming results from slowly decaying changes in the weights on connections between units. Both of these mechanisms would then contribute to the total repetition advantage at short delays.
3. An equivalent characterization can be made in terms of abstractionist versus episodic theories of priming (see Tenpenny, 1995). Abstractionist theories assume that the memory traces responsible for priming preserve only the abstract identity of familiar items, while episodic theories assume that priming relies on novel traces coding the perceptual details of the context in which an item was studied.

4. Without a full understanding of how lexical knowledge is represented, there can be no exact definition of what constitutes psychological wordlikeness. Variables known to affect nonword processing times include phonological structure, bigram frequency, syllabic structure (see, e.g., Dorfman, 1994), frequency of the final segment of the word (see, e.g., Patterson \& Morton, 1985), and number of orthographic neighbors (e.g., Coltheart, Davelaar, Jonasson, \& Besner, 1977). Many of these factors are necessarily confounded with the manipulation we selected.

5. This recombination technique is the obvious approach for examining the contribution of a paired association to priming. However, al though it is suitable for examining long-term priming (Carroll \& Kirsner, 1982), it cannot be used as the primary method here: Lag 0 repeats cannot be primed in different pairs, and even its use at lag 1 rests on the (at best approximately true) assumption that the individual-item effect of repeating both items at lag 1 is equal to the average of repeating one at lag 0 and one at lag 2 .

6. Where data violated the sphericity assumption of repeated measures ANOVA, analyses were conducted via multivariate analysis of variance.

(Manuscript received January 6, 1997; revision accepted for publication June $12,1998$. ) 